TRAMES, 2008, 12(62/57), 3, 342-354

\title{
IDENTITY POLITICS RECO(R)DED: VINYL HUNTERS AS EXOTES IN TIME
}

\author{
Berk Vaher
}

University of Tartu

\begin{abstract}
The article is a study into exotic record collecting as a manifestation of memorybased identity politics - a way of reasserting one's agency in the consumerist society through an expanded consciousness of the complexities of the forgotten cultural past (in the present case, extremely eccentric obscure vinyl records). First, exotic record collecting is linked to the more extensive tradition of utopian exoticism in Western culture - the recycling of cultural memory (thus also an exoticism based on temporal rather than spatial distance) is presented as an extension of the earlier but largely exhausted exoticism which was inspired by alien territories. Next, exotic vinyl hunting is suggested to be the postmodern revival of the cultural project of 'ethnographic surrealism', celebrated by James Clifford as one of the crucial catalysts of modernism. Finally, the connection between exotic record collecting and other reinterpretations of collective cultural memory is indicated, as exemplified by collector Mickey MacGowan's The Unknown Museum, which ventures to expand collective cultural memory of the history of popular culture and thus combat the perennial industrial promotion of the 'new' with more vintage and affective ways of defining oneself through material objects of imagined value.
\end{abstract}

DOI: $10.3176 /$ tr.2008.3.09

Keywords: memory, exoticism, popular culture, vinyl records

"For anyone interested in exploring beyond the boundaries of the contemporary popular music scene, the past is a strange and wonderful place. Much of it is also a realm of amnesia" (Hayward 2000:1).

\section{Introduction}

In 2005, Forever Heavenly released a compilation album called The sounds of Monsterism Island volume one, compiled by Welsh artist Peter Fowler and con- 
taining obscure sonic psychedelia, exotica and electronica. The inside of the sleeve presents a map of the imaginary island with track titles scattered across it topographically.

Fowler is a conspicuous representative of the worldwide community of vinyl collectors - a movement in praise of the vinyl record as an iconic material vehicle of memory in 20th century culture, flourishing in the face of the digital recording revolution of the last decades of the 20th century and expanding in the download 'noughties' of the new millennium. ${ }^{1}$ At the same time, Fowler also represents a special kind of aficionado who goes beyond the threefold division of 'souvenir', 'fetishist' and 'systematic' collecting (Susan Pearce quoted by Roy Shuker 2004: 327). While the three modes refer to nostalgia, quantity and completism respectively, there is a fourth dominant - that of strangeness, which allows for a definition of exotic collecting.

This kind of collecting is an especially fascinating field of study with respect to memory as the basis of identity politics. Memory is inseparable from identity, individual or shared. In the double process of linking and separating Self and Other through selective memory, exoticism breeds in the controversial interzone, accumulating to reverse the habitual patterns of establishing the Self by rooting it in the unforgettably (and also by and large untranslatably) alien. An identity that thrives on exoticism is essentially questioning the entire epistemological framework of embedding individual selves fluently in the consensual understanding of the common cultural past.

This is exemplified by exotic record collecting, which entails the double critique of both academic cultural history and of its alternative in popular culture. Whereas the bulk of Shuker's sample places itself within the stylistic gamut of traditional pop and rock (albeit on its margins in a few cases), the formative principle in exotic collecting is the extremely eccentric or bizarre character of records outside the canon of popular as well as 'high' culture, many of which leave the listener puzzling "how did those 'incredibly strange' records get made?" (collector Chris Long interviewed by Vale and Juno 1994:69) many of which not only lack musical accomplishment but are embarrassing to the point of being 'unlistenable'.

\footnotetext{
Even though vinyl has been a persistent DJ format, Clive Cawley of Mercury Records still states: "Vinyl as a format only survived through the 90s because of its collectability" (De Whalley 2007:72). The same article refers to current rock favourites such as The White Stripes returning to vinyl and underlines that "in 2007, vinyl releases are regarded as the best way to introduce and build up the credibility of a new name to the record-buying public by both independent and major labels alike" (Ibid.: 71). Vinyl hunting is known to fuel major industries of virtual auctioning like eBay; the specialist magazine Record Collector or music magazines with heavy accent on vintage recordings such as Uncut and Mojo have outlived current charts magazines like Melody Maker or Smash Hits. Record Collector turned from black-and-white to full-colour in 2004, introducing a regular interview with a maverick record collector the same year; in 2006, it was shifted from the back pages to one of RC's premier regulars. Peter Fowler was featured in September 2006.
} 
Yet those trying experiences are not just vital for the exotic collector's identity (an outsider redefining him/herself through a relationship with extreme manifestations of otherness) but may also be arranged into a kind of mental sonic utopia (imagined territory/community of such otherness) which in a few cases is communicated back to the broader audiences interested in popular music and cultural history. In this way, collecting becomes something like a shamanic venture into the areas of cultural memory that have been suppressed into the dark subconscious, and having transformed the individual identity, the collection is employed to transform the shared understanding of cultural past. The utopia is brought to life here and now - we all (potentially) share this denied history of sonic eccentricity.

Monsterism Island is a case in point. As a utopian exotic territory created by a bricolage of forgotten (or hardly ever known) tunes, it exemplifies in the most literal manner a number of attitudes of exotic collecting that are outlined in somewhat more dispersed manner in the two-part Incredibly Strange Music by V. Vale and Andrea Juno, published a decade earlier and revered among vinyl hunters as the tomes that reinterpreted the quaint hobby of record collecting as subversive identity politics for postmodernity - a way of reasserting one's agency through expanded consciousness of the complexities of the forgotten cultural past $(1993: 3) .^{2}$

The following article is a study of that identity politics. First, it will be necessary to link exotic record collecting to the more extensive tradition of utopian exoticism in Western culture - a tradition which is itself in the vibrant state of being rediscovered from the archive of politically disreputable cultural mentalities. I aim to show that the recycling of cultural memory (thus also an exoticism based on temporal rather than spatial distance) is an extension of the earlier but largely exhausted exoticism which was inspired by alien territories.

Next, I am going to assess exotic vinyl hunting (as documented by Vale and Juno) as the postmodern revival of the cultural project of 'ethnographic surrealism', celebrated by James Clifford as one of the crucial catalysts of modernism. Finally, I will indicate the connection between exotic record collecting and other reinterpretations of collective cultural memory, as exemplified by collector Mickey MacGowan's The Unknown Museum, which ventures to expand the collective cultural memory of the history of popular culture and thus combat the perennial industrial promotion of the 'new' with more vintage and affective ways of defining oneself through material objects of imagined value.

2 Released in the American alternative cultural studies series Re/Search, in 1993 and 1994 respectively, and containing interviews with 'cult' musicians such as Martin Denny and Korla Pandit (and spoken word acts such as Ken Nordine) as well as record collectors (predominantly Californian, of interdisciplinary artistic backgrounds, and due to the authors' feminist leanings, including female vinyl hunters to a greater percentage than they seem to feature among record collectors at large). 


\section{Modernist exoticism: fabricated memories of authenticity}

The recent treatments of exoticism in Western culture have ranged from sharp critique (much of the post-colonialist theory springing from Said (1978) - Hutnyk (2000) most pertinently to music) to ethnographic inquiry (Clifford 1988) to poetic revitalization (Toop 1999, 2001). The discussion has definitely contributed to the notion of exoticism as not just a by-product of Western colonial expansion but a feature of any culture, an indispensable inspirational (mis)understanding of the Other which defines and redefines Self by transforming the perceiving subject as much as the object - or possibly more.

Yet even granting that, exoticism tends to be regarded as a mode of conceptualizing a distinct geographical and ethnic reality; i.e. establishing an idealized or distorted image of Japan, India, Africa, the Pacific Islands, etc. However, throughout the 20th century the hybridization and emancipation of the exotic imaginary can increasingly be detected; it has become disengaged from the actual places, to be elaborated as a mixture of signs from a rich archive of cultural otherness, creating new fictitious sites in the mind rather than just adding a layer of description to the hitherto existing ones.

The exoticism of imaginary territories is largely conditioned by the exhaustion of the physical faraway: for the wayward fin de siècle artists such as Paul Gauguin, faith in the redeeming 'noble savagery' of particular (is)lands was all but lost. Escape from the industrialized, urban and bourgeois Europe, to discover a more genuine experience of individual and communitarian humanity somewhere closer to nature, only led to encountering transplants of Western civilization/colonization - if not in the exotic environs, then incontestably within the searcher himself.

Thus, the artistic exoticism of modernity became a matter of reverie rather than raiding - that is, a world-scale memory of the lost innocence of humanity; or as Chris Bongie states in his oft-quoted Exotic Memories:

The exoticist project, similar in this respect to the metaphysical tradition, attempts to re-present what has 'always-already' been lost and forgotten; only once thus project has been exhausted does the possibility of truly remembering the exotic arise - of remembering it, that is, as what can never be truly remembered, as what is absent, vanished (1991:26).

What has been lost in the physical world can be recreated in imagination, through obtaining, connecting and systematizing fragments of alien worlds. The imaginary recreation of the exotic Other at the beginning of the 20th century could not help but rely on authentic experiences of the past - or indeed, the experiences that by then appeared to be authentic, or at least suggested the attainability of authenticity in the days of yore; but neither could it any longer entirely count on them. The Other had to be willed into existence and persistence by a subject yearning for diversity, the vanished Golden Age needed to be re-envisaged within, the authenticity of experience realized only through complete fabrication, by the subject eventually turning into a complete stranger to his cultural context - a radical act of autopoesis in the face of an increasingly mass-production society. 
This kind of subject was identified as an 'Exote' by Victor Segalen - a French fin-de-siècle writer and thinker on exoticism whose rediscovery has been concomitant with the broader increase of artistic and academic interest in exoticism at large. Although relatively little known at a time, his approach was exemplary of contemporary attitudes:

[Segalen wrote] from a temporal perspective that already reflected the intense competitive expansion of Euro-America in Africa and Asia. All that was left of the exoticists' dream was an indeterminate elsewhere of difference situated either in the past or the future which only the poet and the dreamer would be able to imagine (Harootunian 2002:xv).

His Essay on Exoticism: An Aesthetics of Diversity is a diary fragmented from 1904-1918, only published partly in 1955 and in full no earlier than 1978. It is especially pertinent for the current theorization of exoticism in modern and postmodern Western culture for its emphasis on the subject, the conscious reconstruction of identity and memory by an Exote - according to the inventor of the term, the one who experiences "the rapture of the subject conceiving its object, recognizing its own difference from itself, sensing Diversity" (Segalen 2002:20).

But Segalen also rallied against colonialist clichés of exoticism which in mass use tended to benumb rather than sharpen the sense of cultural otherness, and suggested alternatives based on cognition rather than travel. In Essay, he is recurrently emphasizing the temporal aspect of exoticism, thus theoretically pioneering science fiction but also pointing out that the past is not hopelessly lost but open for imaginary reliving: "The Exoticism in Time. Going back: history. An escape from the contemptible and petty present. The elsewheres and the bygone days" (Ibid: 24).

At the time, the concept of temporal exoticism remained largely hypothetical (even though any quest for the roots of human culture may be interpreted as temporal exoticism), it has recently been exemplified by the collectors of vinyl exotica, revising the canons of sonically recorded 20 th century.

\section{In the world of sound: collecting and recollecting the past on record}

In his essay on Segalen, James Clifford (2002:155) refers to "[o]ne of his short fictions, 'Dans un monde sonore' [which] imagines a man who chooses to live in a darkened room filled with subtle sounds, who touches and apprehends space acoustically"; Clifford characterizes it as 'beautifully insane' (Ibid.) Not only do the more recent portraits of exotic vinyl hunters charmingly match the image presented by Segalen, but seekers of the 'incredibly strange' memories from the forgotten sonic past can also be seen to reiterate the very foundations of modernity which, as Clifford has indicated, defined itself through extensive collecting of the Other from the suppressed 'savage' history of the mankind.

Clifford (2002:217) theorizes the complex relationship between identity, memory and collecting by drawing on C. B. Macpherson's The Political Theory of 
Possessive Individualism (1962) and its declared fundamentality of owning and organizing to a sense of Western self: "identity, whether cultural or personal, presupposes acts of collection, gathering up possessions in arbitrary systems of value and meaning". Building on the postulate that "[f]aced with the aggressions of everyday life and the passing of phenomena, memory needs objects - always manipulated through aesthetics, selective emphasis, or the mixing of genres" (Hainard and Kaehr 1986:33 cit. in Clifford 2002:231), he proposes a Western cultural framework where 'identity is a kind of wealth' and "collecting has long been a strategy for the deployment of a possessive self, culture, and authenticity ... an exercise in how to make the world one's own" (Clifford 2002:218).

Collecting can be viewed as a foundational or re-establishing process, a search for lost time: "Collecting appears as an art of living intimately allied with memory, with obsession, with the salvaging of order from disorder" (Benjamin 1969 cit. in Clifford 2002:219). Yet this process also unearths 'histories of danger and desire', enabling an excursion into 'a forbidden area of the self' so that "[a]t best ... one can transgress ('poach' in their tabooed zones) or make their self-evident orders seem strange" (Clifford 2002:216-217).

Clifford sees 'ethnographic surrealism' as one of the main tenets of 20th century Western culture, indicating that in the formative stages, those two approaches to culture were intricately entwined and not least in their shared obsession with collecting. The approaches were obverse and thus complementary: ethnography would entail "a rescue of phenomena from inevitable historical decay or loss... what 'deserves' to be kept, remembered, and treasured. Artefacts and customs are saved out of time [to give] form, structure, and continuity to a world", whereas he defines surrealism as "an aesthetic that values fragments, curious collections, unexpected juxtapositions - that works to provoke the manifestation of extraordinary realities drawn from the domains of the erotic, the exotic, and the unconscious" (Ibid: 231, 118).

Ethnography traced order in cultures different from those of the West; surrealism drew on their evidence to suggest (or impose) drastically alternative categorizations in Western culture; retrieval of the global memory merged with that of local memory in decontextualized objects found from antique shops and flea markets to be recontextualized as potentially magical solutions to the present crisis of cultural and moral identity. In brief, they could be perceived as two complementary code locks expected to be shifted into mutually revelatory positions.

That ethnography and surrealism would grow apart from each other is a matter of lament to Clifford and at the same time prompts a call for a reunion of some kind - an ethnography that would include modern Western culture, which for so long has elevated itself into the role of scrutinizing and categorizing subject among passive objects, detached but thus also fatally alienated. Vale and Juno's two above-mentioned volumes of Incredibly Strange Music are not just enthralling examples of such a modern ethnography; they also introduce a whole network of 
already active DIY ethnographic surrealists, researchers as much as artists, reinterpreters of collective memory as well as dreamers on their own sonic islands. ${ }^{3}$

The subcultural self-consciousness of the record collecting community is relatively recent. The practice of collecting vinyl records itself harks back to the early 20th century, as soon as gramophone had gone into mass production (Shuker 2004:313). A number of collectors interviewed by Vale and Juno had been active in the field for decades; yet only when, in the second half of the 1980s, the compact disc started to take over and supersede the vinyl album and single as the commercially preferred vehicle for recorded sound did the practice of collecting vinyl acquire the openly shared rhetoric of a subversive subculture.

By the time Vale and Juno conducted their interviews, the pioneering vinyl hunters were lamenting the onslaught of price guides and a new breed of collectors who were after possessing a high-priced rarity, rather than discovering a forgotten piece of musical history (see e.g. Derek Dickerson in Vale and Juno 1993:132). So, analogically to self-conscious artificial exoticism emerging even as the 'real' experience of exoticism vanished, the image of vinyl-hunting as frontier-pushing identity politics (reclaiming the outsider territories in cultural history) came to life when the activity itself was already well on the way to becoming a large trade.

The introductory words of Vale and Juno are perfectly in line with the defiant hopes of artistic exoticism a century earlier, stating in Volume One that "Incredibly Strange Music explores the sonic territory of vinyl recordings (mostly c. 1950-1980) largely neglected by the music criticism establishment" (2) while Volume Two "continues the exploration of the territory [of] mostly out-of-print vinyl recordings from the '50s-'70s which do not fit into the already critically scrutinized genres of rock, jazz, and classical music [and] collectors who have remapped their own musical aesthetics" (4). The unofficial histories that survive, only in the memories of the more adventurous individuals, offer a whole different world to those unable to conveniently locate their identities in a culture based on the official history. And again, this exploration entails invention as much as discovery:

These pioneers link one recording to another and create genres where none previously existed. The act of an individual creating their own categories and evaluations for any cultural field constitutes a dismantling of the status quo's control system which rules our lives and perceptions through implanted 'aesthetics' - what society deems good or bad (highbrow or lowbrow). ... In an age of information overload, the mere act of wading through and deciphering society's discards becomes a political act ... Thus these records become more

3 For a further elaboration of the anthropological aspects of vinyl collecting presented by Vale, Juno and several other writers, as well as on the larger-scale revival of 'Space Age', 'exotica' and 'lounge' in the 1990s, see Taylor (2001:96-114). Kirsten (2003) also uses the term 'urban archaeology' in his broader-scale study of exoticism in 1950s America. 
than a consumeristic product: they become a reflection of the collector's inner vision and express an alternate aesthetic philosophy (Vale and Juno 1993:3-4). ${ }^{4}$

This manifesto of record collecting as identity politics is confirmed by collector Lynn Peril on the grounds of agency as a declaration of individual authenticity/ audacity:

Adrienne Rich says we live in a culture of 'manipulated passivity' - men and women both are so used to having everything handed to them. You need audacity to find things out for yourself. I happen to love discarded cultural artefacts that are now in thrift stores, and surrounding myself by the things I love is one way to fight this passivity. It's the opposite of consumerism (Vale and Juno 1993:122). ${ }^{5}$

\section{4. '...a recovery centre for cultural amnesiacs'}

Remarkably, the post-war musical genre of exotica is among the most universally represented in the 'incredibly strange' vinyl collections, alongside genres such as "easy listening, promotional, novelty/comedy, religious, soundtracks, spoken word, children, celebrity, as well as instrumental headings like accordion and organ" (Vale and Juno 1993:2). In other words, the record collectors' exoticism in the broad sense - cherishing everything 'out of this (widely known sonic) world' - contains and draws inspiration from the more specific, literal core of exotica. That is not lost on Vale and Juno who observe that Hawaiiana, phallic tikis, sundry outre dance crazes and the particular kind of music popular in 1950s' suburbia suggests an alternative code for a radical

4 For the sake of fairness it has to be added that as any exoticist text, Vale and Juno's introduction is ridden with intriguing contradictions and contains no less naivete than insight, to the point of stating that "[i]n earlier centuries, each tribe or country basically had only one regional type of music available to its citizens (e.g., Bulgarian folk choruses; Moroccan djilala music; Balinese gamelan) but in today's post-technological global village, all music is at our disposal, with exciting new recombinations and cross-pollinations asserting themselves" and that " $[\mathrm{I}] \mathrm{t}$ is now almost possible to have it all. The treasures of 'history' (formerly for only the wealthy ruling elite: books, films, art and music from around the world) are finally becoming accessible." (Vale and Juno 1993:5) Such an ingenuity may be a necessary precondition for a healthy exoticism, however, as long as it fuels the hunger for knowledge rather than complacent conformism.

5 The relationship between visionary collecting and consumerism remains a matter of debate. It is still a reinterpretation of works created by someone else; and even when collecting means going through dusty boxes of torn old obscurities in a charity shop and buying truckloads for a few dollars, it remains part of a market economy. It might have been marginal for the major industries even just a decade ago, but culture industry survives on centring the periphery, and by now the repackaged nostalgia is shunting the current chart acts aside as the major profit maker for record companies, with vinyl sales on the up again as CD sales decrease. Drawing on the works of various researchers of collecting, Shuker (2004) describes collecting as "a socially sanctioned form of materialist and competitive consumption, consumer culture taken to excess" (Vale and Juno 1993:312) but also emphasizes the 'passion' aspect setting it apart from 'standard' consumerism (Vale and Juno 1993:316). For an elaborate discussion of agency in the consumption of popular music, see Taylor (2001). 
reinterpretation of collective memory: "Just as a dream cloaked in symbols can reveal what we have unconsciously suppressed, so music can expose unsurfaced longings and desires and thus grant unexpected insights into our culture." (Ibid.)

In essence, the exotica boom of the 1950s was the replay of the earlier avantgarde ethnographic surrealism on the broader consumerist scale. The cultural otherness therapy implemented by cutting edge European artists in the cultural depression after the First World War $^{6}$ was rediscovered by middle-class Americans after the Second World War; and even though rock'n'roll seemed to do away with the quaint easy listening sounds of exotica, the latter's influence looms large in surf and psychedelia of the following decades, major themes for record collecting in themselves. ${ }^{7}$

That exotica was for decades written out of the rock'n'roll-based pop history only adds to its powers of subversion now, being taken up by punk luminaries who rebel against the exhausted rock mythology as much as against the (neo)conservative Puritanism and high-art elitism of the academic intellectuals. The backbone of vinyl hunters' identity politics is not just industrial/institutional critique; it is also the critique of dissenting artistic/academic culture which has denied the self-expressions which go beyond the range of what's accepted as innovation and may well strike from the very heart of consumer culture. The Orientalist or Tropicalist easy-listening lounge music of the 1950s is a case in point, proving to be new to the critical intellectuals for whom very little is new these days:

If I had ever been aware of this music as a child, I had not recalled it; nor did subsequent encounters trigger any such memories. This made it all the more enticing, a shadowy history, only thinly covered by the sands of time, still retrievable (Hayward 2000:2). ${ }^{8}$

A few record collectors employ this sense of novelty in the service of a largerscale cultural anamnesia, bringing back the memories people have, but are afraid to share, as well as those they were not even granted in their own lifetime in the first place. When plausible, common memories have taken a culture into another cul de sac with all of the institutionalized paradigms failing to deliver, the exotic imaginary helps to rediscover many a selfhood. Stuart Swezey of the alternative publishers Amok Books declares:

For me, there's something archeological about hunting for these records. A thrift store displays all this debris, all these pieces of history that aren't in the

6 "After Europe's collapse into barbarism and the manifest bankruptcy of the ideology of progress, after a deep fissure had opened between the experience of the trenches and the official language of heroism and victory, after the romantic rhetorical conventions of the nineteenth century had proved themselves incapable of representing the reality of the war, the world was permanently surrealist" (Clifford 2002:119).

7 The 1950s exotica is extensively discussed by Toop (2001), Taylor (2001), (2000) and Kirsten (2003).

8 Likewise, Ivy Rorschach of The Cramps has commented upon his discovery of vintage rockabilly and $\mathrm{r} \& \mathrm{~b}$ : "I had never heard this music before so it wasn't nostalgia for me - it was a whole new world" (Vale and Juno 1993:8). 
history books yet illuminate the time. Just as a pottery shard tells you about an ancient civilization, so 'Quiet Village' [the signature exotica tune written by Les Baxter and taken to the top of the charts by Martin Denny] can tell you a lot more about 1958 than a sociology book. Records are the last cheap archeological collectibles... (Vale and Juno 1993:187).

The therapeutic aspect is taken to the furthest by Mickey McGowan - "among the first to collect neglected music (15,000 records)" (Ibid: 98). His main activity for decades has been running the Unknown Museum, characterized by Vale and Juno as:

possibly the world's only archive of over 100,000 American '40s-'90s pop culture artifacts (toys, dolls, lunchboxes, promotional giveaways, etc.) Far more than a trip down Memory Lane, the Unknown Museum preserves America's greatest contribution to art history - unselfconsciously produced pop culture (Ibid.).

Upon Juno's suggestion of the museum being 'like a recovery center for cultural amnesiacs', McGowan elaborates: "I like to think of it as physical therapy, except that it's the memory that's being exercised, not the body. ... the idea is: "There's this Museum; let's go see what we've lived and experienced" (Ibid: 100). Just as with ethnographic surrealism, however, the experience is far from safe; the most mundane of period pieces have the capability of unearthing suppressed traumas; or as McGowan sums up:

The overall environment of this museum is an artistic statement about American culture and its underlying neuroses; its fantasies, daydreams, bad dreams, wet dreams - every kind of dream. It's also the American dream gone haywire. [One is] going inside America's brain...every little thing you see as you walk through the museum is a memory cell reflecting some facet of your past (Ibid: 101).

McGowan's record collection - including huge amounts of vintage exotica helps to enhance the experience. There is also no real contradiction between the exotic escapades and search for grassroots Americana; for a number of collectors, both are out of reach to the mass consumer, both are shut out of the major culture/history industry.

This missionary work compels a few vinyl fiends to venture out into other media. Opting for vinyls as such instead of CDs is still common among collectors; but increasingly, there is the urge to share one's imaginary utopian islands (the spatio-temporal mindscapes outlined by the highlights of their collection) with the CD buying/mp3 downloading public beyond the cognoscenti of the incredibly strange'. Alternative fanzines and radio shows go online, DJ sets end up on record to be sold through collectors' own labels such as Trunk Records (Jonny Trunk), Finders Keepers (Andy Votel) and many others, making changes in the collective consciousness with rare recordings from Turkey, Scandinavia and the former communist bloc being brought to the awareness of people who thought they knew all about pop history by knowing just the tip of the Anglo-American iceberg. "People have complained to me that their favourite thrift store watering holes have dried up after Incredibly Strange Music, Vol. One came out," remarked the 
Californian 'cultural terrorist' Jello Biafra: "So what? Dig deeper. Burn new borders and let the mind fly. For those who stay curious, there are always new frontiers" (Vale and Juno 1994:48). Being one of the not-so-many collectors (and independent label owners) whose speciality was collecting rare records from the past decades of non-Western cultures (Brazil, Africa, former USSR), he knew just how much ethnographic surrealism is yet to be carried out when the century of globalization drew to a close.

\section{Conclusion}

The exotic record collectors who transform their own identity by inhabiting the imaginary utopian territory of 'incredibly strange' sounds and shared cultural history by dropping the needle on forgotten or un-experienced vinyl memories, are just the extreme example of what most of the adventurous record collectors of any kind are doing.

It assumes an awareness that cultural history is written by and through the signification of artefacts. The boundaries of individual cultural freedom are always determined by the collective memory of the ways things have been done - of the possibilities for self-expression, the consensual identity bank with slots for various types of rebels as well as conformists. Those possibilities can and must be negotiated. The tension between individual and collective identity is all too often alleviated at the expense of the former - and one yields to the shared cultural values by becoming ashamed of one's formative pleasures, one's identifying memories; that includes throwing the old records in the basement or bargain bin. Meanwhile, the venturesome vinyl hunter refuses to compromise and turns to everything that has been marginalized in the collective memory.

Recovering those discarded discs and faded fads, creating meanings for and between them, a collector is not only indulging in private pleasures but also indicating that it is possible and even liberating to read the whole grand narrative of culture differently, to measure time your own way - and achieve major-scale revaluations in the narrative. That has been the crucial role of exotes - to explore, experience and express difference; to rearrange emphases in the shared cultural past; to imagine utopian territories which would give a glimpse (or sound) of the fuller gamut of humanity.

I will end with Peter Fowler's sleeve-notes to The Sounds of Monsterism Island (2005):

We all dream of an island paradise from time to time, a place where we can escape the everyday and run free and wild. A few of us may be lucky enough to take a holiday of a lifetime and visit somewhere like Hawaii or the fabulous Isle of Man. There is however a more magical island than these on earth, one that defies the imagination, turns human understanding on its head and dances hand in hand into the surf with your wildest dreams. That place is Monsterism Island and while you won't find it on any map its existence is undeniable. The Sounds 
of Monsterism Island is a window through which the mind's eye of mankind can pass to experience the living beauty of the island.

This compilation is an attempt to convey the many sounds and sights of Monsterism Island in such a way as to leave the listener prepared for the eventual disclosure to the world of its' [sic] existence.

Each recording contained within this long-playing album portrays a different facet of the island's personality. It's [sic] aim is to transport the listener's mind from the rolling surf of the island's golden shores to the summits of its holy mountains, into the depths of deep emerald forests and through the teeming streets of its towns and villages.

\section{Acknowledgements}

The article has been written with support from the Estonian Science Foundation grant No 7162 .

Address:

Estonian Writers' Union

Vanemuise 19

Tartu 51014

Estonia

Tel: + 3727341073

Email: berkvaher@gmail.com

\section{References}

Benjamin, Walter (1969) Illuminations. Hannah Arendt, ed. New York: Schocken Books.

Bongie, Chris (1991) Exotic memories - literature, colonialism and the fin de siècle. Stanford: Stanford University Press.

Clifford, James (2002 (1988)) The predicament of culture: twentieth-century ethnography, literature, and art. Cambridge, London: Harvard University Press.

De Whalley, Chas (2007) "Back to the future. The reissues industry: special report by Chas De Whalley. Part 3: It's in the grooves: the survival of vinyl". Record Collector 339, 70-73.

Fowler, Peter, compiler (2005) The sounds of Monsterism Island. Vol. 1. Forever Heavenly/EMI FHVN 3LPCD.

Hainard, Jacques and Rolland Kaehr (1985) Temps perdu, temps retrouvé: voir les choses du passé au présent. Neuchâtel: Musée d'Ethnographie.

Harootunian, Harry (2002) "The exotics of nowhere." In Victor Segalen. Essay on exoticism: an aesthetics of diversity, vii-xx. Durham and London: Duke University Press

Hayward, Philip, ed. (2000) Widening the horizon: exoticism in post-war popular music. London, Paris, Rome, and Sydney: John Libbey/Perfect Beat Publications.

Hutnyk, John (2000) Critique of exotica: music, politics and the culture industry. London and Sterling, Virginia: Pluto Press.

Kirsten, Sven A. (2003) The book of Tiki: the cult of Polynesian pop in fifties America. Köln: Taschen.

Said, Edward (2003 (1978)). Orientalism. London: Penguin Books. 
Segalen, Victor (2002). Essay on exoticism: an aesthetics of diversity. Durham and London: Duke University Press.

Shuker, Roy (2004) "Beyond the 'high fidelity' stereotype: defining the (contemporary) record collector". Popular Music 23, 3, 311-330

Taylor, Timothy D. (2001) Strange sounds: music, technology and culture. London and New York: Routledge.

Toop, David (1999) Exotica: fabricated soundscapes in a real world. London: Serpent's Tail.

Toop, David (2001 (1995)) Ocean of sound: aether talk, ambient sound and imaginary worlds. London: Serpent's Tail.

Vale, V. and Andrea Juno (1993) Incredibly strange music. Vol. 1. San Francisco: Re/Search Publications.

Vale, V. and Andrea Juno (1994) Incredibly strange music. Vol. 2. San Francisco: Re/Search Publications. 